\title{
The loss of flight in ant workers enabled an evolutionary redesign of the thorax for ground labour
}

\author{
Christian Peeters $^{1 * \dagger}$ (D), Roberto A. Keller ${ }^{2,3+}$, Adam Khalife ${ }^{1,3}$, Georg Fischer ${ }^{3}$, Julian Katzke ${ }^{3}$, Alexander Blanke ${ }^{4}$ and
} Evan P. Economo ${ }^{3}$

\begin{abstract}
Background: Explanations for the ecological dominance of ants generally focus on the benefits of division of labour and cooperation during foraging. However, the principal innovation of ants relative to their wasp ancestors was the evolution of a new phenotype: a wingless worker caste optimized for ground labour. Ant workers are famous for their ability to lift and carry heavy loads, but we know surprisingly little about the morphological basis of their strength. Here we examine the consequences of the universal loss of flight in ant workers on skeletomuscular adaptations in the thorax for enhanced foraging on six legs.

Results: Using X-ray microcomputed tomography and 3D segmentation, we compared winged queens and wingless workers in Euponera sikorae (subfamily Ponerinae) and Cataglyphis savignyi (subfamily Formicinae). Workers are characterized by five major changes to their thorax: i) fusion of the articulated flight thorax (queens) into a rigid box optimized to support the muscles that operate the head, legs and abdomen, ii) redesign of internal cuticular structures for better bracing and muscle attachment, iii) substantial enlargement of the neck muscles for suspending and moving the head, iv) lengthening of the external trochanter muscles, predominant for the leg actions that lift the body off the ground, v) modified angle of the petiole muscles that are key for flexion of the abdomen. We measured volumes and pennation angles for a few key muscles to assess their increased efficacy. Our comparisons of additional workers across five genera in subfamilies Dorylinae and Myrmicinae show these modifications in the wingless thorax to be consistent. In contrast, a mutillid wasp showed a different pattern of muscle adaptations resulting from the lack of wing muscles.
\end{abstract}

Conclusions: Rather than simply a subtraction of costly flight muscles, we propose the ant worker thorax evolved into a power core underlying stronger mandibles, legs, and sting. This contrasts with solitary flightless insects where the lack of central place foraging generated distinct selective pressures for rearranging the thorax. Stronger emphasis is needed on morphological innovations of social insects to further our understanding of the evolution of social behaviours.

Keywords: Formicidae, Mutillidae, Queen, Micro-CT, Muscles, Endoskeleton, Central place foraging

\footnotetext{
*Correspondence: christian.peeters@upmc.fr

${ }^{\dagger}$ Christian Peeters and Roberto A. Keller contributed equally to this work.

As the original corresponding author, Christian Peeters, is deceased, correspondence

should be addressed to Evan Economo (evaneconomo@gmail.com).

'Institut d'Écologie et des Sciences de l'Environnement, Sorbonne Université,

CNRS, 75005 Paris, France

Full list of author information is available at the end of the article
}

\section{BMC}

C C The Author(s). 2020 Open Access This article is licensed under a Creative Commons Attribution 4.0 International License, which permits use, sharing, adaptation, distribution and reproduction in any medium or format, as long as you give appropriate credit to the original author(s) and the source, provide a link to the Creative Commons licence, and indicate if changes were made. The images or other third party material in this article are included in the article's Creative Commons licence, unless indicated otherwise in a credit line to the material. If material is not included in the article's Creative Commons licence and your intended use is not permitted by statutory regulation or exceeds the permitted use, you will need to obtain permission directly from the copyright holder. To view a copy of this licence, visit http://creativecommons.org/licenses/by/4.0/ The Creative Commons Public Domain Dedication waiver (http://creativecommons.org/publicdomain/zero/1.0/) applies to the data made available in this article, unless otherwise stated in a credit line to the data. 


\section{Background}

Ants are among the most abundant terrestrial animal groups, and the benefits of division of labour within colonies is thought to be the central factor in their ecological success. Ants stand out from social bees and wasps because their workers are universally flightless. This striking morphological differentiation between castes avoids trade-offs and optimizes for ground abilities. Ant reproductives (queens and males) need to fly when they are young, but workers are freed from the need to find mates and disperse. Instead, ant workers are famous for their abilities to lift and carry objects [1-5], suggesting adaptations for enhanced foraging on six legs. The morphology underlying those enhanced abilities, however, remains unclear.

All social insects are central place foragers-food is brought back to the nest instead of being eaten on the spot-and the physical ability to retrieve comparatively large amounts of food is paramount [6]. While the workers of social bees and wasps bring back their food by flight, ant workers transport food by walking. Importantly, ant workers are strong enough to lift and carry aloft prey and other food items, unlike various solitary predatory wasps that drag prey when too large to retrieve by flight. Foraging efficiency is also impacted by speed of walking, while running is essential to escape from predators (in contrast, wasps and bees escape by flight). Moreover, the abdomen can serve to hold food reserves, while deftness of its tip is essential in predation and defense to sting or spray formic acid (The sting has its own set of muscles for extrusion and retraction).

The thorax (known as 'mesosoma' in Apocritan hymenopterans because it includes the usual three segments fused with the first true abdominal segment, called propodeum [7-9]) bears the wings and legs, and it supports the head and abdomen, hence it is subjected to oftenconflicting mechanical constraints. Keller et al. (2014) [10] identified a shift in the relative size of the external dorsal plates (where muscle fibres attach) in the anterior thorax as a critical difference between winged queens and flightless ant workers. Reduction of the mesonotum (dorsal plate of the second thoracic segment, T2) and concomitant expansion of the pronotum (dorsal plate of T1) in workers reflect a trade-off: elimination of flightrelated structures allows increased neck muscles in the prothorax. However, the posterior external plates vary little between queens and workers, and it remained unclear if there is also remodelling of the endoskeleton and muscles transmitting force to the legs and abdomen. Among the Hymenoptera, only ant workers and a few solitary parasitoids (e.g. females of Chyphotidae, Mutillidae, and Tiphiidae) are wingless. The anatomy of the wingless thorax was investigated early on by Lubbock (1881) and Janet (1907) [7, 11], described externally by
Tulloch (1935) and Reid (1941) [9, 12], and recently described using 3D reconstruction [13]. Despite this accumulation of data over more than a century, the morphological consequences of wing loss have hardly been investigated.

Winglessness in ant workers has been considered a reduction to facilitate mobility in cramped environments [6], without examining consequences on thorax architecture. We hypothesized that the evolution of a worker caste freed from the anatomical and functional constraints of flight is a critical innovation that allowed the remodelling of the thorax for ground labour. Using Xray microcomputed tomography (micro-CT), we performed detailed segmentation to compare conspecific workers and winged queens in two distantly related exemplar genera, Euponera (subfamily Ponerinae) and Cataglyphis (Formicinae). We show significant fusion of external plates and modifications of endoskeleton, neck, leg, and petiole muscles. We confirmed this in a phylogenetically broad sample of ant genera (Table 1). We discuss that ant workers have a distinct thorax relative to other wingless insects (including solitary wingless hymenopterans), and explain this as a function of sociality and living in perennial nests: central place foraging selects for optimal gathering of food.

\section{Methods}

\section{Taxon selection}

We focused on two species with workers of similar body sizes, belonging to distantly related ant subfamilies. Euponera sikorae is a generalized species in the subfamily Ponerinae, and a good example of the lowest queen-worker dimorphism in ants, likely to represent the ancestral condition [14]: the thorax of workers remains generally stout, with parallel sides and an uninterrupted dorsum (Additional file 1). Cataglyphis savignyi is an exemplar of the large subfamily Formicinae, and illustrates a pronounced level of queen-worker dimorphism [15]: the thorax of workers is slender, especially in its middle (Additional file 2). Head width of workers varies from 1 to $3 \mathrm{~mm}$ (N. Lecocq de Pletincx pers. comm.), and we scanned an individual similar in body size to the queen.

The most recent common ancestor of Cataglyphis and Euponera is a deep node in the ant phylogeny [16]. Thus, it is likely that any similarity in thorax design between these two taxa is shared by most ants. Our primary analysis concentrates on two species because micro-CT analysis is labour-intensive. However, we have examined scans of workers from a number of genera across the ant phylogeny (Table 1) to verify that the changes we describe are general features of the ant thorax. We also examined the thorax of a solitary Mutillid wasp, representing an independent loss of flight within the Hymenoptera. 
Table 1 Thorax modifications resulting from the lack of wing muscles in additional taxa from three ant subfamilies (Dorylinae, Formicinae, Myrmicinae) and a female mutillid wasp (subfamily Mutillinae, tribe Smicromyrmini or Trogaspidiini) examined by microCT and SEM

\begin{tabular}{|c|c|c|c|c|c|c|c|}
\hline Subfamily & Species & $\begin{array}{l}\text { Fusion of external } \\
\text { plates (SEM)? }\end{array}$ & $\begin{array}{l}\text { Angle of } \\
\text { profurca } \\
\text { platform? }\end{array}$ & $\begin{array}{l}\text { Origin of direct } \\
\text { head muscle } \\
\text { IdIm } 1 \text { ? }\end{array}$ & $\begin{array}{l}\text { Indirect muscle } \\
\text { Idvm5 } \\
\text { enlarged? }\end{array}$ & $\begin{array}{l}\text { Origin of mid- \& } \\
\text { hindlegs trochanter } \\
\text { muscles? }\end{array}$ & $\begin{array}{l}\text { Enlarged } \\
\text { petiole } \\
\text { muscles? }\end{array}$ \\
\hline Formicinae & $\begin{array}{l}\text { Colobopsis } \\
\text { truncata }\end{array}$ & $\begin{array}{l}\text { articulated } \\
\text { pronotum and } \\
\text { mesonotum }\end{array}$ & more vertical & mesonotum roof & pronotum larger & mesonotum roof & $\begin{array}{l}\text { entire } \\
\text { propodeum } \\
\text { roof }\end{array}$ \\
\hline Dorylinae & $\begin{array}{l}\text { Dorylus } \\
\text { wilverthi }\end{array}$ & $\begin{array}{l}\text { promesonotal } \\
\text { fusion }\end{array}$ & more vertical & mesonotum roof & pronotum larger & mesonotum roof & entire roof \\
\hline Myrmicinae & $\begin{array}{l}\text { Carebara } \\
\text { perpusilla }\end{array}$ & $\begin{array}{l}\text { promesonotal } \\
\text { fusion }\end{array}$ & more vertical & absent $^{\mathrm{a}}$ & pronotum larger & mesonotum roof & entire roof \\
\hline Myrmicinae & $\begin{array}{l}\text { Melissotarsus } \\
\text { beccarii }\end{array}$ & $\begin{array}{l}\text { promesonotal } \\
\text { fusion }\end{array}$ & more vertical & absent $^{\mathrm{a}}$ & extremely large & mesonotum roof & $\begin{array}{l}\text { highly } \\
\text { reduced a }^{\text {a }}\end{array}$ \\
\hline Myrmicinae & $\begin{array}{l}\text { Messor } \\
\text { barbarus }\end{array}$ & $\begin{array}{l}\text { promesonotal } \\
\text { fusion }\end{array}$ & more vertical & mesonotum roof & pronotum larger & mesonotum roof & entire roof \\
\hline Myrmicinae & $\begin{array}{l}\text { Pheidole } \\
\text { oculata }\end{array}$ & $\begin{array}{l}\text { promesonotal } \\
\text { fusion }\end{array}$ & more vertical & mesonotum roof & pronotum larger & mesonotum roof & entire roof \\
\hline $\begin{array}{l}\text { Mutillinae } \\
\text { (Mutillidae) }\end{array}$ & unidentified & $\begin{array}{l}\text { promesonotal } \\
\text { fusion }\end{array}$ & tilted back & absent ${ }^{b}$ & $\begin{array}{l}\text { no, smaller than } \\
\text { petiole }\end{array}$ & mesofurca for midlegs & $\begin{array}{l}\text { past midlegs } \\
\text { only }\end{array}$ \\
\hline
\end{tabular}

associated with miniaturisation

${ }^{b}$ linked to hypognathy

Euponera sikorae was collected in Madagascar (Zahamena NP, Toamasina province); Cataglyphis savignyi in Israel (Arad Park); subfamily Mutillinae (tribe Smicromyrmini or Trogaspidiini) in Uganda (Kanyawara Biological Station, Kibale).

\section{Specimen preparation and micro-CT scanning}

Micro-CT scans were carried out at OIST using a Zeiss Xradia 510 Versa 3D X-ray microscope. Ant specimens were stored in $90 \%$ ethanol, then stained in a $2 \mathrm{M}$ iodine solution for a minimum of $24 \mathrm{~h}$ and transferred into pipette tips filled with $99 \%$ ethanol before scanning. Scan settings such as current, voltage, and exposure were adjusted for each specimen to yield maximum scan quality. Full 360 degree rotation resulted in 1601 projections. Scans had resolutions of $993 \times 1013 \times 988$ pixels (vertical stitching increased this to 3159 / $3514 \times 1013 \times 988$ pixels for Euponera and Cataglyphis queens, respectively). Post-imaging 3D reconstruction was performed using the Zeiss Scout-and-Scan Control System Reconstructor software (version 11.2) and output files were saved in DICOM format.

\section{Cuticle thickness measurements}

Scan files were loaded into Drishti 2.6.5 [17] to generate 3D models. Two 'Clipping Planes' were positioned at a $90^{\circ}$ angle across pronotum and propodeum to get the most accurate measurements of cuticle thickness. For every plane, a 'Viewport' was added to visualize the section, and ten measurements were made on each section (clockwise, numbered from 1 to 10; Additional file 3) using the 'Path' function.

\section{Segmentation}

We assessed homologies of muscles and sclerites relative to Apis mellifera [18] in which both workers and queens are winged. Muscle nomenclature follows Friedrich \& Beutel 2008 and Liu et al. 2019 [13, 19]: for example, Idvm 5 denotes a dorsoventral muscle in $\mathrm{T} 1$ inserting on the propleura (ventral plate), while IIscm6 is a sternocoxal muscle in $\mathrm{T} 2$ inserting on the trochanter.

We combined Amira 6.3.0 and ITK-SNAP 3.6.0 [20], with manual segmentation every five to ten slices followed by either the 'Interpolation' tool in both softwares or the 'region competition' algorithm for semiautomatic segmentation in ITK-SNAP. Subsequently, we manually cleaned the edges of automatically segmented structures, in particular between neighbouring muscles that are difficult to recognize as separate structures by the algorithm.

\section{Muscle volume measurements}

Muscle segmentations were exported as mesh files (.stl) from ITK-SNAP into the software Blender 2.81 (www. blender.org). Spaces between fibres result from shrinkage during ethanol preservation, and we integrated over entire muscle segmentations. After scaling using voxel size, we fitted a 3D object (usually an Icosphere) to each muscle mesh. We achieved good fit using (1) the "subsurface" modifier on the 3D object to create more polygons and (2) the "shrinkwrap" modifier to fit this 3D object around the muscle mesh. We measured the volume of this 3D object and used it as the physiological muscle volume. In case of a poor fit, we split the muscle mesh into two meshes of simpler shapes and fitted 3D 
objects separately. Volumes were then normalized (Additional file 9) using the volume of the inner thorax which was segmented with Amira by selecting the space enclosed by cuticle, after closing the openings for head, leg and petiole insertions.

\section{Fibre tracing and angle measurement}

Vertebrate muscles have mostly parallel fibres between points of attachment (e.g. bone extremities), thus measuring physiological cross-sectional area (PCSA) is meaningful to infer muscle force. In contrast, insect locomotory muscles can 'spread out' as they increase in size, i.e. additional fibres attach to a greater area of the endo- and exoskeleton, then converge to a tendon. Hence, pennation angles are more relevant to distinguish between efficient and less efficient fibres. We selected segmented petiole muscles of Euponera to compare pennation in queen and worker. We traced individual fibres with Amira XTracing 2019.2 and used Blender 2.81 to calculate the angle between each fibre and the direction of force production of the respective muscle (Katzke et al. in prep.). In this approach, the coordinate system defined by the micro-CT image stack is utilized to treat orientations of anatomical features as vectors.

\section{Results}

While ant queens retain the ancestral thorax morphology of flying Hymenoptera, we identified five major deviations of the worker thorax involving the exoskeleton, endoskeleton, neck muscles, leg muscles, and petiole muscles. Although our discussion focuses on Cataglyphis and Euponera, these modifications are present across all the ant workers examined (Table 1). Together, they represent the evolution of an enhanced power core for more effective foraging on six legs.

\section{Fusion of the flexible articulated thorax into a rigid thoracic box}

The thorax of a winged insect is essentially a flying engine with powerful wing muscles that vibrate articulated external plates called sclerites. As in other winged Hymenoptera, ant queens have huge indirect wing muscles (41 and 52\% of thorax volume in Euponera and Cataglyphis, respectively) that fill the prominent mesothorax (T2) but also adjacent segments (Figs. 1c and Fig. 2). This is because the longitudinal muscles are attached to flexible cuticular invaginations (phragmata) of the mesonotum that extend into both the prothorax (T1) towards the front and the propodeum (IA) towards the back (Fig. 2; the metathorax, T3, is much reduced dorsally and only serves for insertion of the hindwings [8]). Hence, much of the relatively small cavity of the prothorax of ant queens is occupied by wing muscles, with the neck muscles squeezed against the exoskeletal outer wall.

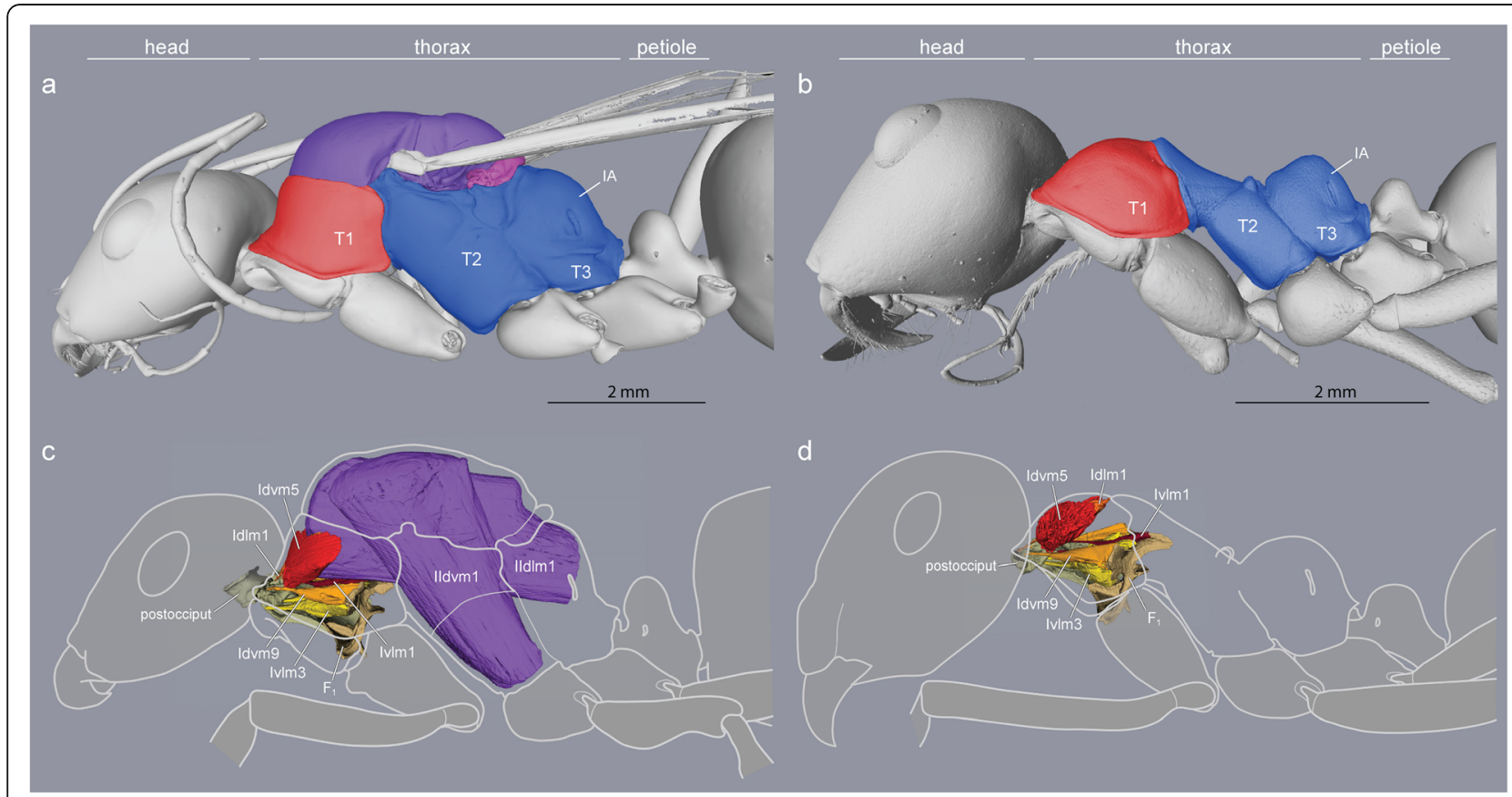

Fig. 1 Caste differences in fusion of thoracic plates and presence/absence of wing muscles (Cataglyphis savignyi). a A large mesonotum (purple) in queens freely articulates dorsally, and $\mathbf{c}$ carries huge wing muscles (purple) that occupy most of the thoracic cavity. b The mesonotum in workers is much reduced and fully fused with the posterior section of the thorax to form a rigid box-like structure (blue). $\mathbf{d}$ Neck muscles in workers (red, orange, yellow) expand in the absence of wing muscles within the enlarged anterior thoracic cavity ( $\mathrm{B}$, red). $\mathrm{T} 1$, prothorax. $\mathrm{T} 2$, mesothorax. T3, metathorax. IA, propodeum 


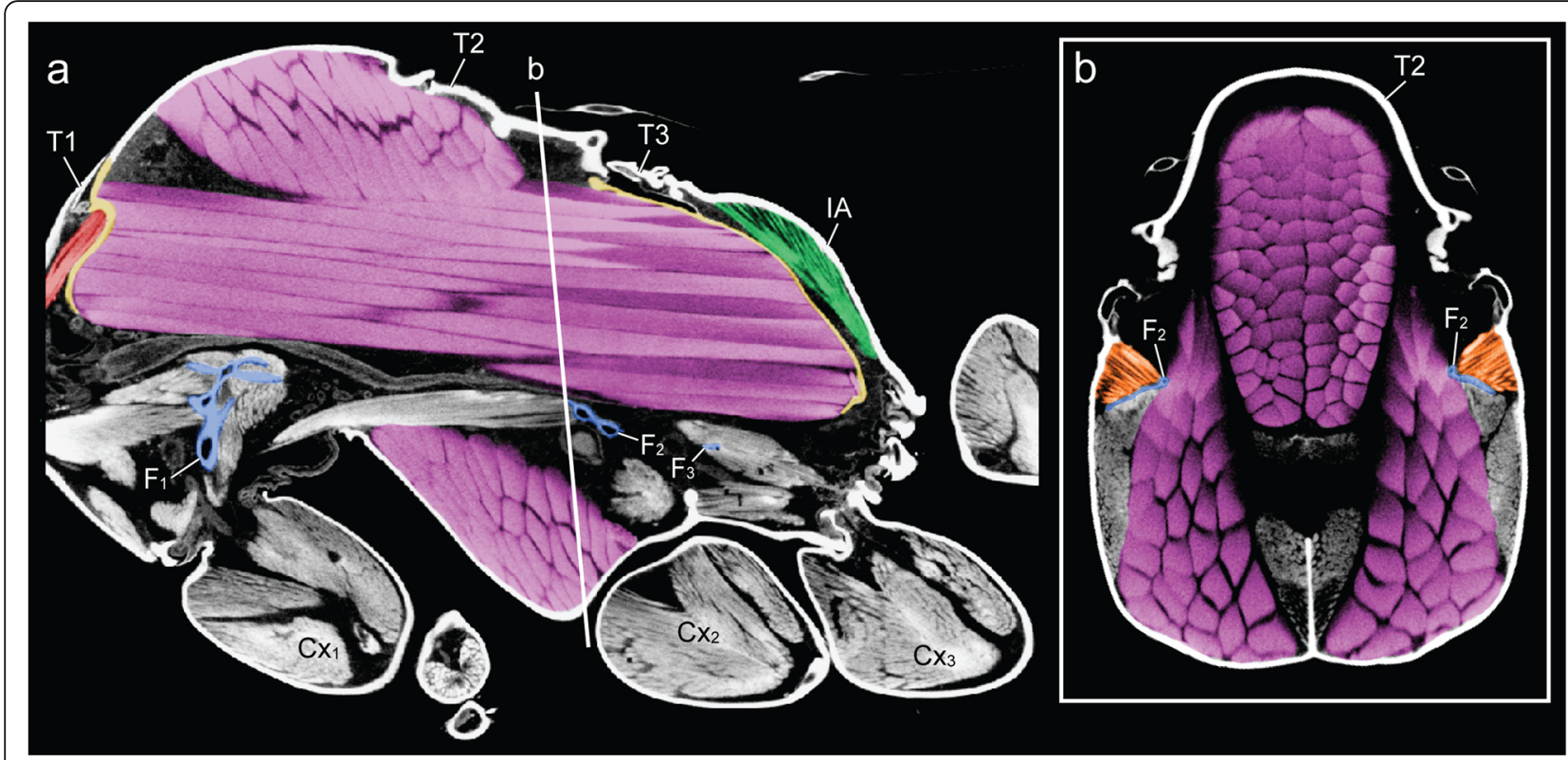

Fig. 2 Constraints of the wing muscles (purple) on the height of the furcae (blue) and volumes of neck (red) and petiole (green) muscles in thorax of Cataglyphis savignyi queen. a Sagittal section from micro-CT scan. Note the anterior and posterior phragmata in yellow. $\mathbf{b}$ Transverse section through mesothorax, showing the muscular connection (orange) between the mesofurca (blue) and the lateral thoracic walls. T1-3, pro-, meso-, and metathorax respectively. IA, propodeum. F1-3, pro-, meso-, and metafurca respectively. Cx1-3, fore-, mid-, and hindcoxa respectively

Flapping of the wings is achieved not by direct muscle action, but by vibration of the entire thoracic box caused by the indirect wing muscles that deform the dorsal plates to which the wings are attached [21]. Flexibility of the thorax and free articulation of the dorsal plates (Fig. 1a) are thus essential for flying, and winged ant queens conform to the general groundplan of Hymenoptera.

Ant workers lack wing muscles and the corresponding phragmata, and the plates of T2, T3 and IA are fused into a single rigid structure forming the posterior twothirds of the thorax (Fig. 1b, Additional file 1). The first third is the prothorax (T1) housing all the muscles that move the head, and it is greatly enlarged dorsally [10].

Thickness of Euponera cuticle is about three times that of Cataglyphis, in both queens and workers (Additional file 3). Thickness varies according to dorsal or lateral position of measurements within one segment, and variability is higher within one individual than between castes. Mean thickness is similar for workers and queens except for the propodeum of Cataglyphis.

\section{Redesign of the endoskeleton for optimized bracing and muscle attachment}

Inside the thoracic cavity, three invaginations of the sternae (ventral plates) rise up in front of each pair of legs, forming a row of rigid forked pillars. These furcae function as internal attachments for muscles that run between segments (head-to-prothorax, prothorax-to-mesothorax, metathorax-to-petiole), and muscles that move the legs (Fig. 3). In queens, the main stem of the furcae rise not more than one-third of the thorax's height before bifurcating towards the sides (Fig. 4). This configuration results from the constraint of the huge longitudinal wing muscles that occupy the top two-thirds of the thoracic cavity (Fig. 1c and Fig. 2). In workers, the loss of wing muscles freed space within this cavity, allowing changes in size and shape of all three furcae.

The furcae of T2 and T3 are ancestrally fused into a single structure [18] (Fig. 3). The T2 furca bears a narrow transverse bridge that connects the distal points of its forked arms (Additional file 4). In winged Hymenoptera, these lateral arms connect with the walls of the upper thorax via a short muscle, providing the necessary flexibility for flight. In ant workers this muscular connection is lost, and we found that the T2 +3 furcal arms are fused with the walls of the thorax, forming an internal bracing structure that possibly increases the overall rigidity of the thoracic box.

In contrast with the short and fused $\mathrm{T} 2+3$ furcae, the profurca (T1) is larger and more elaborate across Hymenoptera. Both the median stem and the forked lateral arms are stout and support a sizeable bridge, shaped like a thin platform (Additional file 5). This platform provides attachment surfaces for three neck muscle pairs on its anterodorsal side (muscles Idvm9, Ivlm1, and Ivlm3) and a key foreleg muscle on its posteroventral side (see 


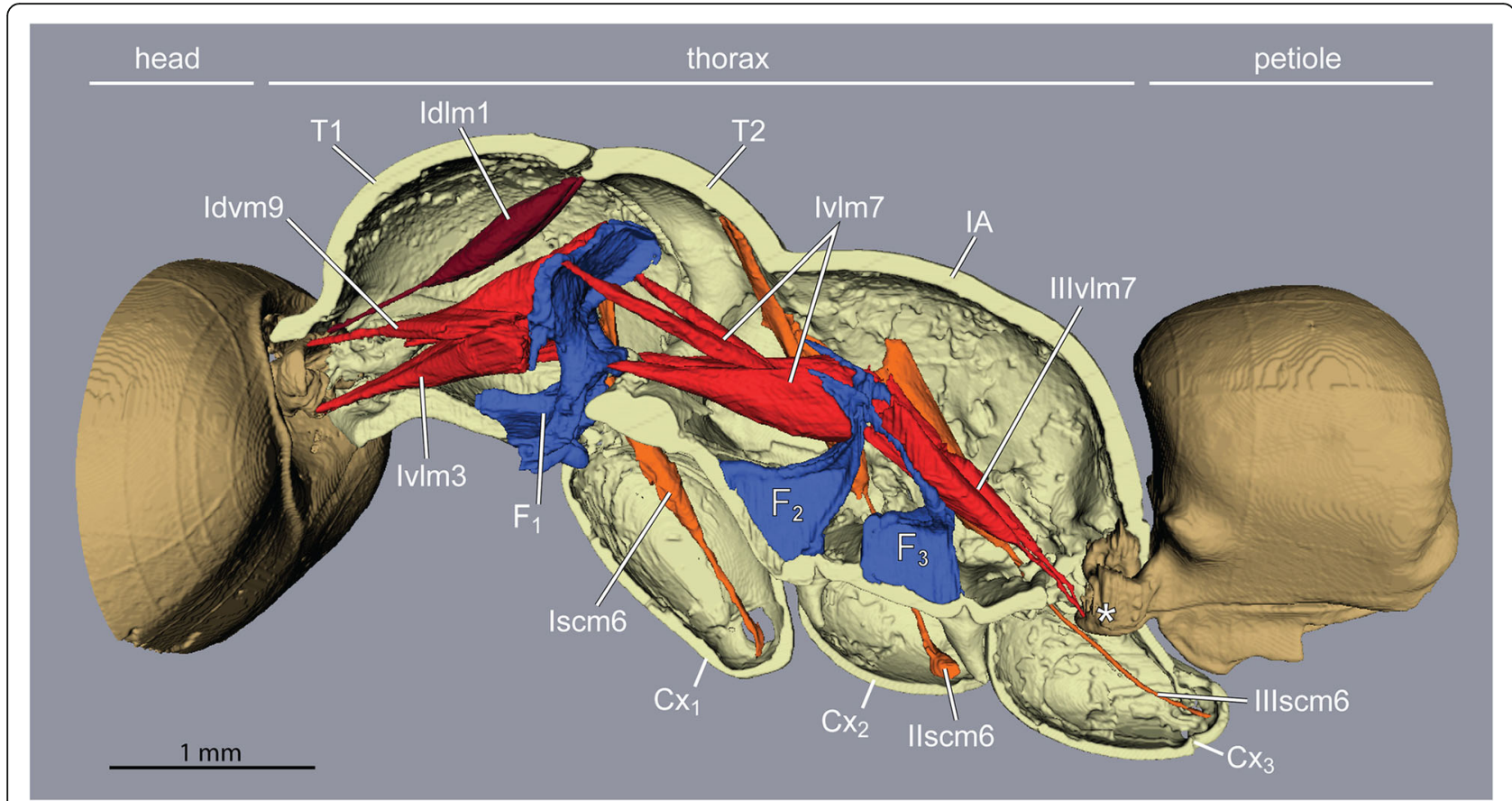

Fig. 3 Tension muscles (red) connect head, furcae, and petiole along the thorax in ant workers (Euponera sikorae). Furcae (blue) are skeletal structures that relay force/stress inside the thorax. A direct muscle (Idlm1) originates dorsally at anterior edge of the mesonotum and pulls the head up. External trochanter muscles (orange, right legs only). Posteriorly, muscles arising on metafurca insert on the anterior end of the petiole, pulling the abdomen to maintain horizontality. T1, prothorax. T2, mesothorax. $F_{1}$, profurca. $F_{2}$, mesofurca. $F_{3}$, metafurca. $C x_{1}, C x_{2}$ and $C x_{3}$ are coxae (= first segments) of the fore-, mid- and hindlegs respectively

below). In flying queens, this platform is horizontal to allow the longitudinal wing muscles and oesophagus to run dorsally (discussed in Keller et al. 2014 [10]). Consequently, the neck muscles attach to the platform at a low angle. However, the lack of wing muscles in ant workers removes this constraint, and the platform takes a more vertical orientation resulting in a greater attachment surface and more favourable angles of origin for the large muscles that insert directly on the back of the head and support it (see below).

Unlike the $\mathrm{T} 2+3$ furcae, the profurca is not fused with the thorax walls, instead its median stem articulates freely in front of the foreleg insertions while its lateral arms connect to the thorax walls with membranes and a short muscle [8]. The neck muscles act antagonistically to both foreleg muscles (see below) and the intersegmental muscles (Ivlm7) that connect the profurca with $\mathrm{T} 2+3$ furcae (Fig. 3), transmitting stress from the head to all legs. Similarly, posture is maintained at the back of the thorax with intersegmental muscles (IIIvlm7) connecting $\mathrm{T} 2+3$ furcae to the petiole to transmit stress from the abdomen to the thoracic box.

\section{Reorganization of the neck muscles}

The neck articulation in Hymenoptera is composed of four skeletal elements (Additional file 6): the postocciput, a short cup-shaped extension of the back of the head; a pair of triangular propleura that are ventrally situated in T1; and the profurca which sits inside T1. The head's postocciput has a strong articulation with the thorax via a stiff neck membrane [22] as well as the anterior apodemes of the propleura [18]. The propleura are never fused to one another and these large plates can shift antagonistically for sideways and rotational movement of the head [23].

No muscles inside the head are involved in the movement of the head relative to the thorax. Rather, all neck muscles are prothoracic, moving the head either directly by inserting on the postocciput or indirectly by inserting on the propleura. In both queens and workers, four pairs of direct muscles lift the head up-and-down (Fig. 1c-d and Additional file 5). The lack of the anterior phragma in workers (associated with loss of wing muscles) affects especially muscle pair Idlm 1 . In queens, Idlm 1 originates at the sides of their pliable phragma (Additional file 7), while in workers Idlm1 originates further back at the anterior margin of the roof of T2 (part of the rigid thoracic box; Fig. 3). Consequently, the better anchoring of muscle Idlm1, its extra length and lower angle of insertion to the postocciput (Additional file 7) give greater support and strength to the worker head in comparison to that of winged queens. The direct muscles Itpm1 


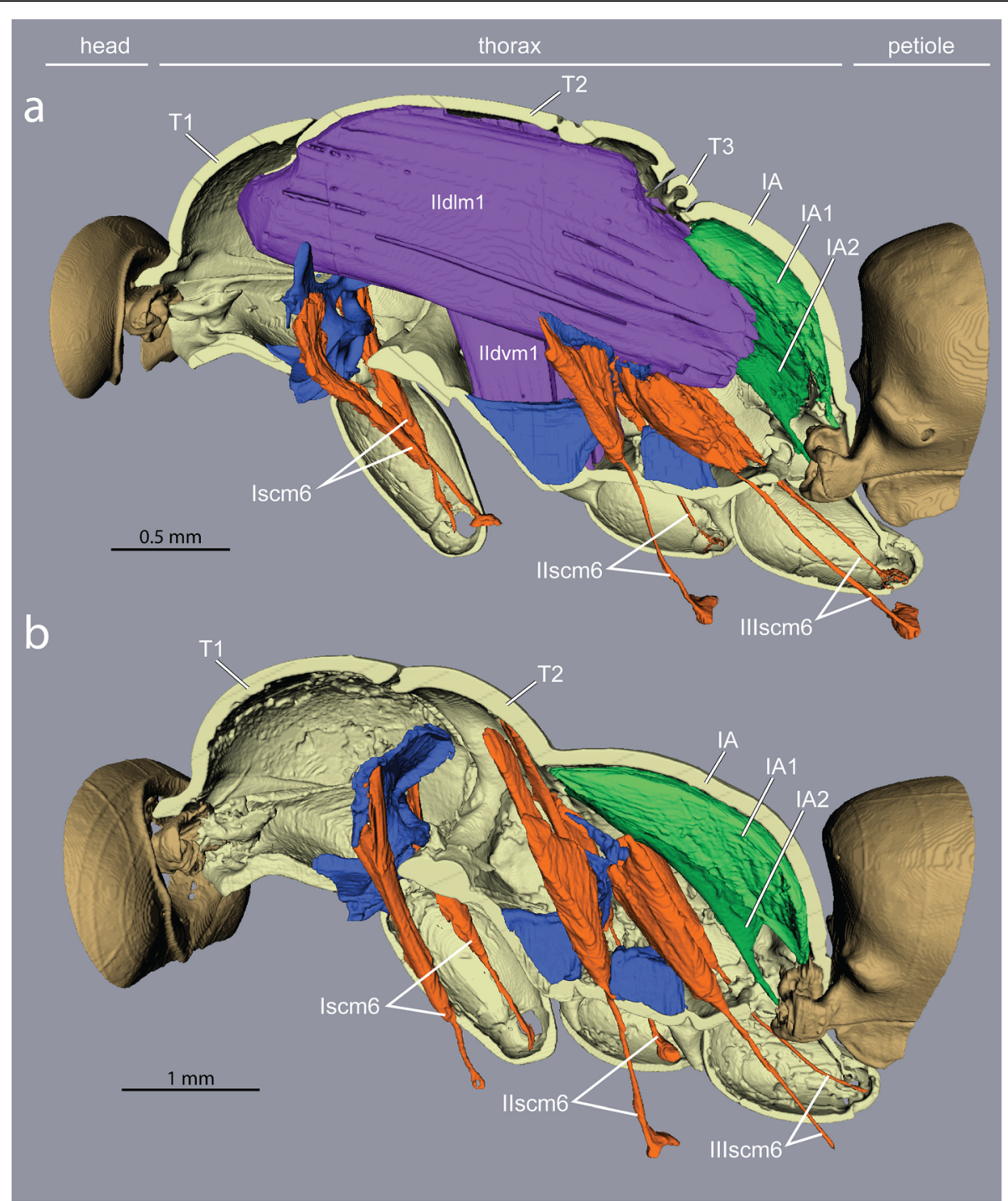

Fig. 4 Impact of loss of wing muscles on geometry of leg muscles and petiole levators in Euponera sikorae. a In queens, wing muscles fill the thoracic cavity, limiting the size of leg and petiole muscles. $\mathbf{b}$ In workers, the external trochanter muscles (orange) of the midlegs (Ilscm6) and hindlegs (Illscm6) are extended to originate high on the roof of the mesothorax (T2) and the lateral walls of propodeum (IA) respectively, while the levators of the petiole (green) are larger and fill up almost the entire propodeal cavity

originate at the base of propleura, hence their geometry differs little between queens and workers, but Itpm1 is relatively larger in workers for both species (Fig. 6). In contrast, muscle pairs Idvm 9 and Ivlm3 are considerably affected by the queen-worker difference in the angle of the profurca platform $\left(26^{\circ}\right.$ and $53^{\circ}$ in Euponera queen and worker, respectively; $16^{\circ}$ and $30^{\circ}$ in Cataglyphis queen and worker; Additional file 5). In queens, as in wasps and bees, this platform is almost horizontal, and thus, these muscles have a very shallow angle to their origin. Contrary to queens, the upright inclination of the platform in workers allows a more favourable perpendicular angle of origin and a greater attachment surface for the equivalent muscles.
Two indirect muscle pairs are mostly responsible for sideways and rotational head movement by inserting on the anterior ends of the propleura. Ivlm1 originates on the profurca and thus benefits from the more favourable inclination of its platform in workers (Additional file 5). Idvm5 shows the most spectacular difference between queens and workers (Additional file 7). This large muscle pair originates at the pronotum (dorsal plate of T1) which is considerably larger across all worker ants. In addition to the increased area of attachment, the absence of wing muscles allows this muscle to support the propleura from a diagonal rather than a vertical angle. Both Idvm 5 and Ivlm1 are relatively larger in workers for both species (Fig. 6). 


\section{One crucial leg muscle differs between workers and flying queens}

Back and forth movements of insect legs are controlled by a series of short muscles that originate within the thorax and insert around the opening of the coxae, the basalmost segment of each leg that articulates with the body. Leg flexion and extension, on the other hand, are controlled by muscles that reside entirely within the segments of the legs [18]. A notable exception is the external trochanter muscles. One per leg (Iscm6, IIscm6, IIIscm6), these muscles originate in the thorax but end in a long tendon that crosses the coxae and inserts on the trochanter (second leg segment) of all legs (Figs. 4 and 5).
Contraction of the external trochanter muscles causes depression of the leg, lifting the body and carrying the ant's weight plus any load. Because these muscles are housed outside the legs, with only their tendons crossing the coxae, their action is independent from the rotational motion of the coxae, and force is transmitted efficiently from the thorax to the legs no matter if walking or standing.

While the muscles of the coxae and those internal to the legs do not differ much between the castes, our segmentations show that the external trochanter muscles are very distinct in length, geometry, and place of origin between queens and workers. In queens, the external trochanter muscles are shorter because they originate on the

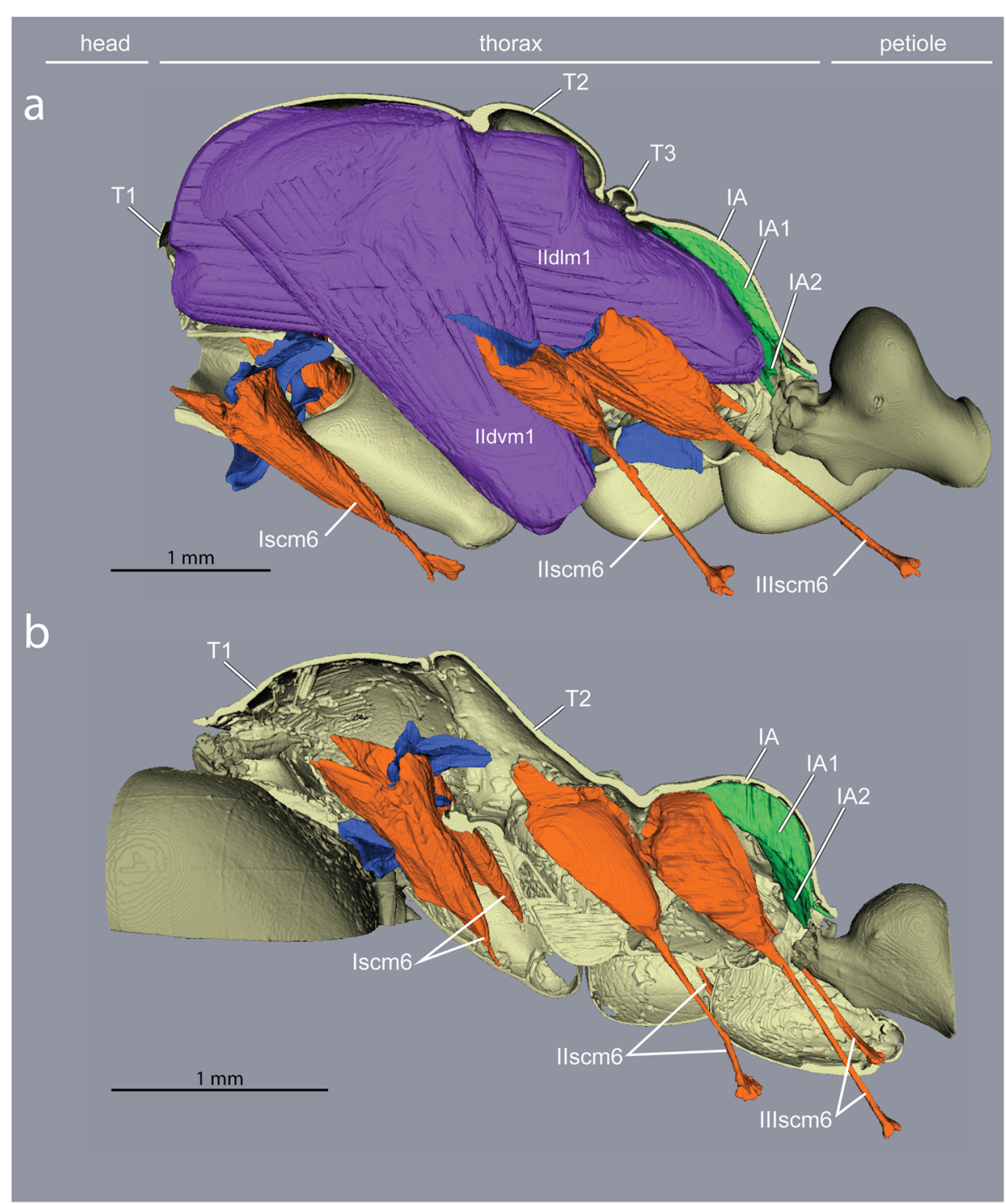

Fig. 5 Loss of wing muscles and geometry of leg muscles and petiole levators in Cataglyphis savignyi. a In queens, wing muscles restrict both leg and petiole muscles. $\mathbf{b}$ In workers, the external trochanter muscles (orange) of the midlegs (Ilscm6) and hindlegs (IIlscm6) are extended to originate high on the roof of the mesothorax (T2) and the lateral walls of propodeum (IA) respectively, while the levators of the petiole (green) increased in volume to fill up almost the entire propodeal cavity. T2/T3 furcae are not shown. Note thinner cuticle relative to Euponera (Fig. 4) 
furcal arms of their respective segment, just below the longitudinal wing muscles (Figs. 4 and 5). The absence of wing muscles in workers allows dorsal elongation of the mid and hind external trochanter muscles (IIscm6, IIIscm6), which attach either on the roof (Cataglyphis) or lateral walls (Euponera) of the rigid thoracic box (Figs. 4 and 5, Additional file 8). Queen-worker differences are minor for the forelegs: in both castes external trochanter muscles Iscm 6 originate at the lower surface of the T1 furcal platform (Figs. 4 and 5). These muscles, therefore, act antagonistically to the neck muscles originating at the upper surface of this platform, helping to pull the head and transmitting force effectively from the head-neck articulation to the front legs. Workers in both species have a relatively larger IIscm6 than queens, and in Cataglyphis Iscm6 and IIIscm6 are also larger (Fig. 6).

\section{Enlargement of the petiole muscles}

As with the head, all muscles responsible for articulating the free part of the abdomen are housed inside the thorax. Four muscle pairs (two dorsal, two ventral) insert on the anterior narrow end of the petiole, which protrudes in the back of the thorax. By acting antagonistically to each other, these muscles control both vertical and horizontal movements of the abdomen [18].

Our segmentations show that the two dorsal pairs differ strongly between queens and workers due to the presence/absence of the flight apparatus (Figs. 4 and 5). Muscles IA1 and IA2 originate on the roof of the propodeum (middle and lateral, respectively), but because of the posterior end of the horizontal wing muscles in queens, these petiole muscles are squeezed in the narrow space between the posterior phragma and the exoskeleton (Fig. 2). In workers, the lack of wing muscles means that muscles IA1 and IA2 fill most of the propodeal cavity (Figs. 4 and 5). Although relative muscle volumes are similar between queens and workers (Fig. 6), differences stand out in the fibre geometry in E. sikorae. First, IA1 has longer fibres in the worker than in the queen despite the smaller size of workers. In addition, IA1 fibres attach

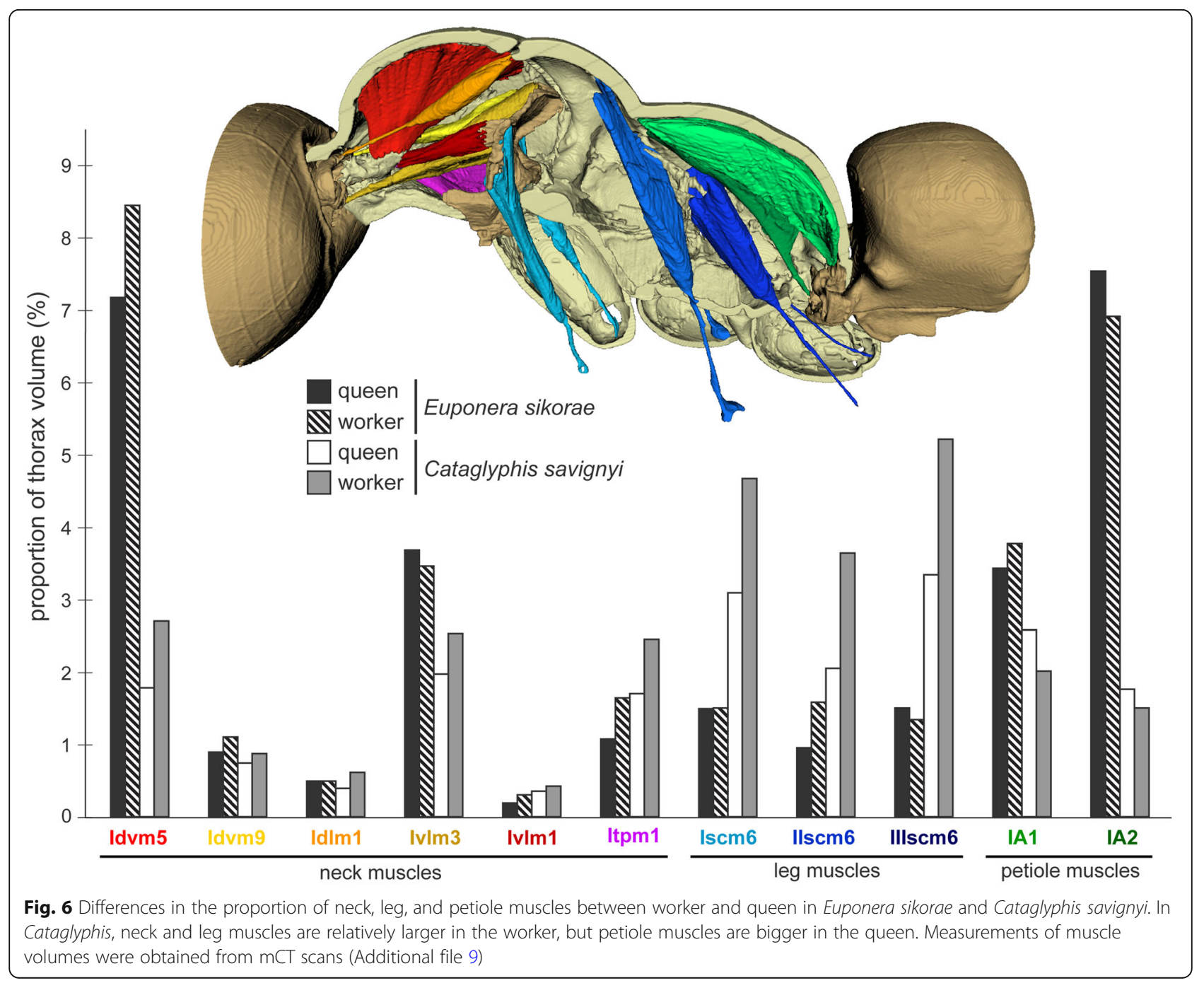




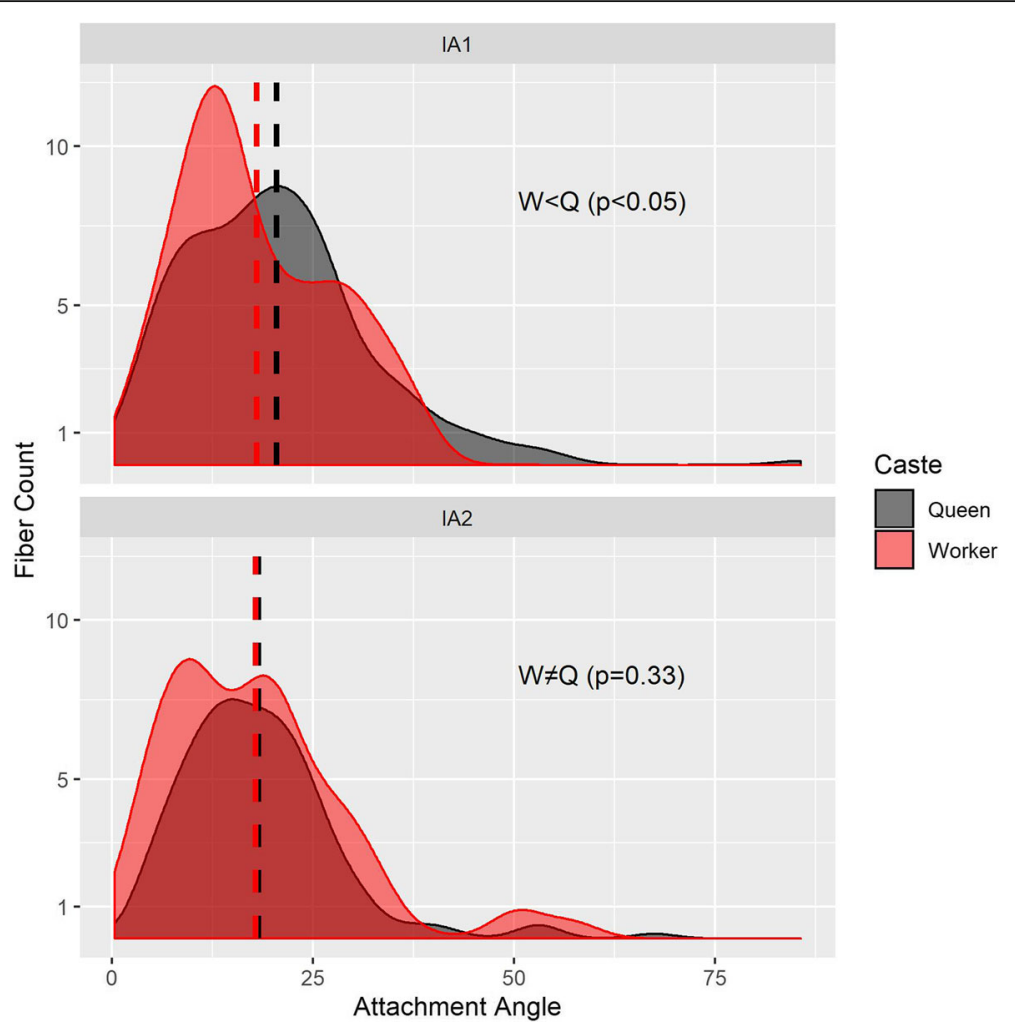

Fig. 7 Distributions of fibre angles for the dorsal petiole muscles (top IA1; bottom IA2; see Additional file 8) differ between Euponera sikorae queen (grey) and worker (red). Fibres with an angle of $0^{\circ}$ contract in the same direction as the force exerted by the muscle, hence lower angles mean more efficient fibres. Dashed line indicates mean angle. According to Mann-Whitney rank sum tests for non-normally distributed data, attachment angles in IAI are significantly lower in worker than in the queen $(W=27,911, p<0.05)$. There is no significant difference in distribution of angles between worker and queen in IA2 ( $W=18,231, p=0.33)$

at significantly lower angles in the worker, resulting in greater efficiency (Fig. 7). Second, IA2 fibres are longer in the queen and attachment angles are not significantly different between worker and queen. However, the worker has $30 \%$ more muscle fibres with a broad distribution of angles, revealing how much this muscle can fan out in the absence of wing muscles.

Marked differences between the two different subfamilies are seen in muscles IA1 and IA2 of workers. In Euponera workers, these petiole muscles originate on the entire roof of the elongated propodeum (Fig. 4). In contrast, in the dome-shaped propodeum of Cataglyphis, the equivalent muscles do not extend forward and are relatively smaller in the worker than in the queen (Fig. 5); instead the anterior roof is the origin for the external trochanter muscles (IIIscm6) of the hind legs (Additional file 8).

\section{Comparison with other flightless insects}

Flight is the ancestral state across the insect tree of life, and its evolutionary loss occurred multiple times independently [24]. While a broad survey of flightlessness across insects is beyond the scope of this paper, we considered whether the modifications described here are specific to social as opposed to solitary lifestyles. In general, the lack of massive wing muscles does not lead to the same modifications of the thorax in solitary taxa. A female mutillid wasp shows strikingly enlarged abdomen muscles (there is no petiole), attached to most of the dorsal roof and reaching the anterior mesonotum (Fig. 8). This is congruent with the origin of the external trochanter of midlegs on T2 furca, instead of the propodeum roof. Given that mutillids are parasitoids that search for hosts underground and oviposit on the spot [25], this difference in thorax rearrangement likely reflects the absence of any selective pressures for prey transport. Indeed, added strength is not necessarily adaptive in solitary insects that are not central place foragers. In flightless moths (Lepidoptera) [26], ovaries reach into the posterior thorax, and the posterior phragma is retained to shield the ovaries; head muscles are not affected compared to flying males. Beetles (Coleoptera) fly with their hind wings only, hence flight musculature is confined to their enlarged T3 and does not conflict with the neck articulation. A functional approach makes it possible to interpret the internal 


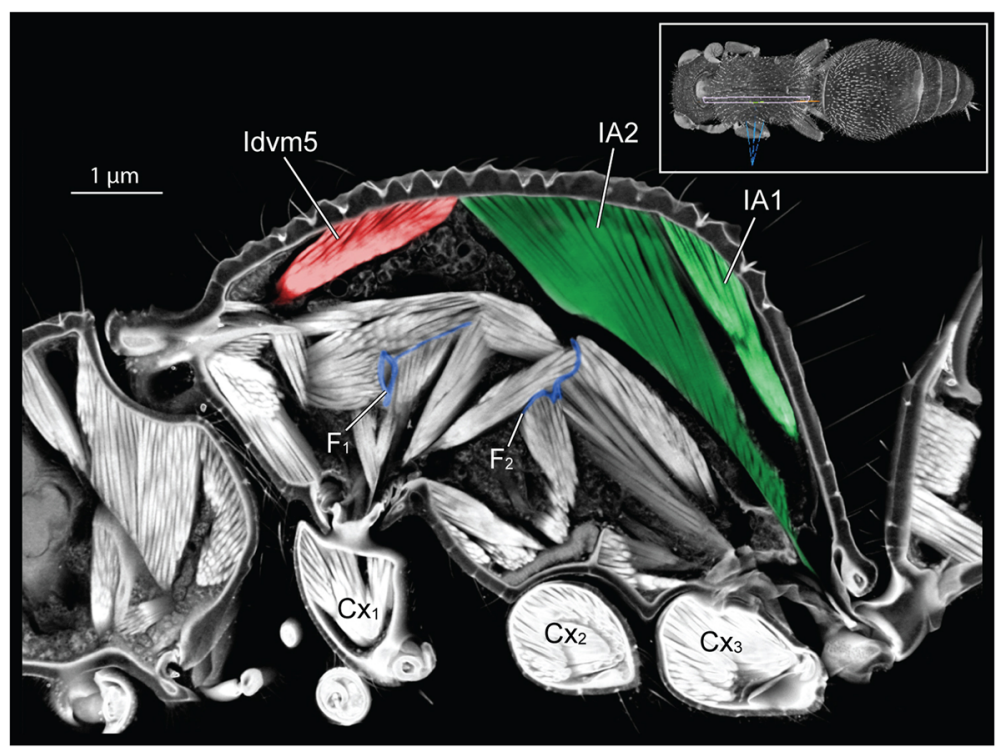

Fig. 8 Three-dimensional section through the thorax of female mutillid (subfamily Mutillinae, tribe Smicromyrmini or Trogaspidiini). Inset (top right) indicates the plane of virtual sectioning. Note the greatly enlarged abdomen muscles (IA1 and IA2) that attach more anteriorly than in ant workers

adaptations associated with wing loss across insects showing divergent ground plans.

\section{Discussion}

Modifications in the thorax of wingless ant workers

Our micro-CT comparison of queens and workers in two distant subfamilies reveals that the evolutionary loss of the flying engine typical of insects allowed for a remodelling of the thoracic skeleton and associated muscles to power earthbound activities. We showed workerspecific modifications in the three endoskeletal furcae that are key for muscle attachment as well as transmission of load between mandibles, legs and abdomen. Our measures of muscle volumes and pennation angles confirmed the conspicuous pattern of repositioning and enlargement seen in 3D segmentations. We highlight the importance of indirect muscles in the prothorax that move the head sideways by shifting two ventral plates (propleura). These adaptations for strength likely result from the selective pressures of central place foraging, that necessitates carrying or dragging food to the nest. Strength is not a general feature of flightless insects but rather an adaptation for maximizing the acquisition of resources for ant colonies. In contrast, solitary mutillid wasp females use vacant space in the thorax for much enlarged abdomen muscles, allowing for better performance as a stinging parasitoid.

Our comparative survey across phylogenetically disparate species revealed a consistent pattern of expanded muscles with altered geometry (Table 1). Although all ant workers have a similarly modified thorax relative to queens, there are minor differences reflecting trade-offs in abilities across lineages. Many ponerines, especially "tanklike" ones such as Euponera, need more strength to manoeuver the sting and hold the heavy abdomen level. By contrast, formicines like Cataglyphis are highly gracile, fast-running ants with a relatively small gaster, thin cuticle, and they lack a sting. While Euponera workers use the expanded propodeal roof for petiole muscles only (IA1 and IA2, Fig. 4), in Cataglyphis the more dome-shaped propodeum is used as attachment surface for both the petiole and hindleg muscles (Fig. 5). Our m-CT segmentations of Euponera and Cataglyphis queens confirm earlier reports [10] of differences in neck muscles contingent on the need to forage or not during colony foundation; the prothorax of non-claustral Euponera queens is more similar to workers' (Additional file 1, Figs. 4 and 5).

\section{Functional morphology of the thorax in ants}

We describe here the morphological redesign of the thorax, and present hypotheses about its functional implications, but it remains a challenge to directly link morphology with performance. A comprehensive modeling effort focusing on the ant thorax is needed to definitively link structure and function, but this presents a formidable challenge. Although we measured the volumes and angles for a few muscles, mathematical analysis of how these changes relate to greater strength or faster contraction speed remains difficult in insects. Moreover, cuticle parameters such as thickness and elasticity need to be integrated in the analysis, but our results indicate that cuticle 
thickness changes across different regions of an individual thorax. Hence simplifying thickness to single values for each individual is a source of errors that complicates mathematical models. Future studies need to refine the biomechanical connection between skeletomuscular specialization of each subsystem (neck, legs and petiole) and overall strength.

The ability to carry heavy prey or liquid food, and to manipulate objects, allows a broader range of potential food items (arthropods live or dead, seeds, honeydew or other sweet secretions) and nest constructions. While activities inside the nests may be less reliant on athletic abilities, foraging encompasses carrying and dragging food, running to escape predators, and the ability to defend and hunt (e.g. mandible dexterity, stinging or formic acid spraying). Given that ant queens retain the ability to disperse by flight in most species, workers were free to combine morphological adaptations for ground labour and social skills. So many benefits derive from the loss of flight in ant workers that, until now, musculoskeletal modifications have been overlooked. In addition to obvious energy savings related to lost wing muscles, both manufacture and maintenance [27], the loss of flight in workers was a decisive innovation that revolutionized colonial economy cheaper workers allow for more populous colonies whenever this is adaptive [28].

\section{Conclusions}

The attributes of individual phenotypes are likely just as crucial to the evolution of social life as genetic caste differentiation mechanisms, chemical communication, kinrecognition systems, and collective behaviour algorithms. Both morphology and social behaviour need to be integrated to contrast the colonial benefits of having wingless workers in ants as opposed to winged workers in social bees and wasps. All worker castes in Hymenoptera evolved specializations for tasks complementary to those of the queen caste, but the chasm is much less dramatic in social wasps and bees because the workers need to fly. Our insights in the adaptations of a thorax rearranged for strength on six legs reveal that ants maximized the merits of having queen and worker castes, allowing for a much greater divergence in body size compared to social bees and wasps. We propose this redesign of the worker phenotype for ground labour combined with the benefits of sociality is key to understanding the ecological success of ants.

\section{Supplementary information}

Supplementary information accompanies this paper at https://doi.org/10. 1186/s12983-020-00375-9.

Additional file $13 \mathrm{D}$ reconstruction of the thorax of Euponera sikorae queen (A) and worker (B). Note that the pronotum is almost the same size in both castes, unlike in Cataglyphis (Fig. 1).
Additional file $\mathbf{2}$ Cataglyphis savignyi worker, sides and dorsum compressed to give mid-thorax the appearance of an hourglass.

Additional file $\mathbf{3}$ Measurements of cuticle thickness for Cataglyphis and Euponera queens and workers. Using virtual slices through the pronotum (purple) and propodeum (green) of 3D models, cuticle thickness was measured at ten different locations, labelled 1 to 10. Values (in $\mu \mathrm{m}$ ) for each location and specimen are shown in the Table.

Additional file 4 Video showing how external trochanter muscles (orange) of mid- and hindlegs originate on the platform of furcae T2 and T3 (blue) in Cataglyphis savignyi queens. These furcae are merged into a single structure with the forked arms of the smaller T3 furca extending forward to fuse with the lateral arms of T2 furca. Depressor muscles of the petiole (light blue) originate on the base of T3 furca. https://doi.org/ 10.5281/zenodo.3406985.

Additional file $\mathbf{5}$ Geometry of neck muscles in prothorax of Cataglyphis savignyi queen versus worker, showing attachments with postocciput (left) and platform of profurca (right). A-D, dorsal view. E-G, lateral view. In $\mathrm{E}-\mathrm{F}$, the highest (a) and lowest (b) points of the platform were used to measure platform inclination (PI). Scale bars $=0.5 \mathrm{~mm}$.

Additional file $\mathbf{6}$ Skeletal neck articulation of Cataglyphis savignyi queen. (A) Ventral view. (B) Lateral view. Pronotum (dorsal) not shown.

Additional file $\mathbf{7}$ Ventral views of prothorax showing neck muscles in queens and workers of Euponera sikorae and Cataglyphis savignyi. Loss of flight muscles (dark blue) allows expansion and reorientation of direct muscle Idlm1 (orange) and indirect muscle Idvm5 (red).

Additional file 8 (A) Dorsal view of 3D reconstruction of muscles attached on the propodeum and posterior furcae of Cataglyphis savignyi worker. (B) and (C) Transverse 2D cross-sections at anterior and posterior planes. Furcae T2 + T3 in blue, external trochanter IIscm6 in salmon, external trochanter IIIscm6 in red, coxa muscle in yellow, petiole muscle IA1 (levator) dark green, IA2 (sideways movement) light green, IIIvIm2 (depressor) pale green.

Additional file 9 : Table S1. Muscle volumes in worker and queen of Euponera sikorae and Cataglyphis savignyi. Muscle volumes were normalized using the inner thorax volume (after excluding the volume of wing muscles in queens) to compare allometry between workers and simplified (wingless) queens. Wing muscles represent 41 and 52\% of the inner thorax in E. sikorae and C. savignyi respectively. Ratios superior to 1 indicate hyperallometry in the worker.

\section{Acknowledgements}

We thank Serge Aron for providing specimens of Cataglyphis, Francisco HitaGarcia for the scanned Mutillidae, Denis Brothers for identification of the Mutillidae, Nathan Lecoca de Pletincx for morphometric data on C. savignyi. We thank the OIST Imaging Section for access to the CT-Scanner.

\section{Authors' contributions}

C.P., R.A.K. and E.P.E. conceived of the study. C.P. and R.A.K. designed the experiments; A.K., J.K. and G.F. conducted the experiments; C.P., R.A.K., A.K., G.F., J.K. and E.P.E. analysed the data; and C.P., R.A.K., A.B., G.F., A.K. and E.P.E. wrote the manuscript. All authors read and approved the final version of the manuscript. C.P. and R.A.K. contributed equally. All authors of the manuscript have read and agreed to its content and are accountable for all aspects of the accuracy and integrity of the manuscript.

\section{Funding}

Subsidy funding to OIST (A.K., E.P.E., R.A.K., and G.F.); collaboration agreement between FCiencias-ID (Portugal) and OIST (R.A.K.); JSPS KAKENHI (JP17K15180) grant (E.P.E.). AB was supported by the European Research Council (ERC) under the European Union's Horizon 2020 research and innovation program (grant agreement No. 754290, "Mech-Evo-Insect").

\section{Availability of data and materials}

All datasets are deposited on Zenodo https://dx.doi.org/xxxx

Competing interests

We have no competing interests 


\section{Author details}

'Institut d'Écologie et des Sciences de l'Environnement, Sorbonne Université, CNRS, 75005 Paris, France. ${ }^{2}$ Museu Nacional de História Natural e da Ciência \& CE3C-FCUL, Universidade de Lisboa, Lisbon, Portugal. ${ }^{3}$ Biodiversity and Biocomplexity Unit, Okinawa Institute of Science and Technology Graduate University, Onna, Okinawa 904-0495, Japan. ${ }^{4}$ Institute for Zoology, Biocenter, University of Cologne, 50674 Cologne, Germany.

Received: 23 June 2020 Accepted: 3 September 2020

Published online: 19 October 2020

\section{References}

1. Bernadou A, Felden A, Moreau M, Moretto P, Fourcassié V. Ergonomics of load transport in the seed harvesting ant Messor barbarus: morphology influences transportation method and efficiency. J Exp Biol. 2016:219:2920-7.

2. Dejean A, Leroy C, Corbara B, Roux O, Céréghino R, Orivel J, et al. Arboreal ants use the "Velcro ${ }^{\oplus}$ principle" to capture very large prey. PLoS One. 2010;5: e11331

3. Moll K, Roces F, Federle W. How load-carrying ants avoid falling over: mechanical stability during foraging in Atta vollenweideri grass-cutting ants. PLoS One. 2013:8:e52816

4. Sudd JH. The transport of prey by ants. Behaviour. 1965;25:234-71.

5. Wojtusiak J, Godzińska EJ, Dejean A. Capture and retrieval of very large prey by workers of the African weaver ant, Oecophylla longinoda (Latreille 1802). Tropical Zoology. 1995;8:309-18.

6. Hölldobler B, Wilson EO. The ants. Cambridge: Belknap Press of Harvard University Press; 1990.

7. Lubbock J. III. On the anatomy of ants. Transactions of the Linnean Society of London. 2nd series. Zoology. 1881;2:141-54.

8. Snodgrass RE. The thorax of the hymenoptera. Proceedings of the United States National Museum. 1910;39:37-91.

9. Tulloch GS. Morphological studies of the thorax of the ant. Entomologica Americana. 1935;15:93-130.

10. Keller RA, Peeters C, Beldade P. Evolution of thorax architecture in ant castes highlights trade-off between flight and ground behaviors. eLife. 2014;3 Available at: http://elifesciences.org/lookup/doi/10.7554/eLife.01539 [Accessed 25 May 2017].

11. Janet $C$. Anatomie du corselet et histolyse des muscles vibrateurs, après le vol nuptial, chez la Reine de la Fourmi (Lasius niger); 1907. Ducourtieux et Gout.

12. Reid JA. The thorax of the wingless and short-winged hymenoptera. Transactions of the Royal Entomological Society of London. 1941;91: 367-446.

13. Liu S-P, Richter A, Stoessel A, Beutel RG. The mesosomal anatomy of Myrmecia nigrocincta workers and evolutionary transformations in Formicidae (hymenoptera). Arthropod Systematics \& Phylogeny. 2019;77: 1-19.

14. Peeters C, Fisher BL. Gamergates (mated egg-laying workers) and Queens both reproduce in Euponera sikorae ants from Madagascar. African Entomology. 2016;24:180-7.

15. Peeters $\mathrm{C}$, Aron $\mathrm{S}$. Evolutionary reduction of female dispersal in Cataglyphis desert ants. Biol J Linn Soc. 2017;122:58-70.

16. Borowiec ML, Rabeling C, Brady SG, Fisher BL, Schultz TR, Ward PS, Compositional heterogeneity and outgroup choice influence the internal phylogeny of the ants. Mol Phylogenet Evol. 2019;134:111-21.

17. Limaye A. Drishti: a volume exploration and presentation tool. In: Stock SR editor. developments in X-ray tomography VIII International Society for Optics and Photonics; 2012. p. 85060X.

18. Snodgrass RE. Anatomy of the honey bee. Ithaca: Comstock Pub. Associates; 1956.

19. Friedrich F, Beutel RG. The thorax of Zorotypus (Hexapoda, Zoraptera) and a new nomenclature for the musculature of Neoptera. Arthropod Structure \& Development. 2008;37:29-54

20. Yushkevich PA, Piven J, Hazlett HC, Smith RG, Ho S, Gee JC, et al. Userguided 3D active contour segmentation of anatomical structures: significantly improved efficiency and reliability. Neurolmage. 2006;31: 1116-28.

21. Dudley R. The biomechanics of insect flight: form. Function: Evolution (Princeton University Press); 2002.
22. Nguyen V, Lilly B, Castro C. The exoskeletal structure and tensile loading behavior of an ant neck joint. J Biomech. 2014:47:497-504.

23. Berry RP, Ibbotson MR. A three-dimensional atlas of the honeybee neck. PLoS One. 2010;5:e10771.

24. Wagner DL, Liebherr JK. Flightlessness in insects. Trends Ecol Evol. 1992;7: 216-20.

25. Brothers DJ, Tschuch G, Burger F. Associations of mutillid wasps (hymenoptera, Mutillidae) with eusocial insects. Insect Soc. 2000:47:201-11.

26. Liu S-P, Wipfler B, Nitsu S, Beutel RG. The thoracic anatomy of the male and female winter moth Nyssiodes lefuarius (Lepidoptera: Geometridae) and evolutionary changes in the thorax of moths and butterflies. Org Divers Evol. 2017;17:565-94

27. Marden JH. Variability in the size, composition, and function of insect flight muscles. Annu Rev Physiol. 2000;62:157-78.

28. Peeters C, Ito F. Wingless and dwarf workers underlie the ecological success of ants (hymenoptera: Formicidae). Myrmecol News. 2015;21:117-30.

\section{Publisher's Note}

Springer Nature remains neutral with regard to jurisdictional claims in published maps and institutional affiliations.
Ready to submit your research? Choose BMC and benefit from:

- fast, convenient online submission

- thorough peer review by experienced researchers in your field

- rapid publication on acceptance

- support for research data, including large and complex data types

- gold Open Access which fosters wider collaboration and increased citations

- maximum visibility for your research: over $100 \mathrm{M}$ website views per year

At $\mathrm{BMC}$, research is always in progress.

Learn more biomedcentral.com/submissions 